\title{
Long-term seismogenesis and self-organized criticality
}

\author{
Frank Evison ${ }^{1}$ and David Rhoades ${ }^{2}$ \\ ${ }^{1}$ School of Earth Sciences, Victoria University of Wellington, P.O. Box 600, Wellington, New Zealand \\ ${ }^{2}$ Institute of Geological and Nuclear Sciences, P.O. Box 30-368, Lower Hutt, New Zealand
}

(Received December 11, 2003; Revised March 24, 2004; Accepted March 30, 2004)

\begin{abstract}
The principles of self-organized criticality (SOC) provide a framework for understanding the process by which individual earthquakes are generated. The SOC principles of fractality, scaling, hierarchy, and extreme sensitivity to initial conditions, are exhibited by the precursory scale increase $(\Psi)$ phenomenon, which we interpret as evidence of a long-term generation process. We have accordingly included SOC in a three-stage faulting model of seismogenesis. Fractality is represented by the Gutenberg-Richter relation, which is relied on for analysing the precursory scale increase $(\Psi)$ phenomenon. Scaling characterizes the parameters of space, time and magnitude that relate the precursory seismicity to the mainshock and aftershocks. The validity of these relations is supported by application of the EEPAS model. Scaling also underlies the Mogi criteria, which are invoked to explain a selfgenerated transient effect, and hence the long duration of the seismogenic process. Hierarchy clarifies the otherwise complex situations that arise when two or more earthquakes are in process of generation at overlapping places and times. Extreme sensitivity to initial conditions explains why, with rare exceptions, both the seismogenic process and the culminating earthquake are initiated with no recognizable immediate trigger. The only exception so far observed for the seismogenic process is the proposed triggering, on 1992.06.28, of the long-term Hector Mine (California) process by the nearby Landers mainshock.
\end{abstract}

Key words: Seismogenesis, self-organized criticality, fractals, scaling, hierarchy.

\section{Introduction}

The realization that self-organised criticality (SOC) applies to earthquakes (Bak and Tang, 1989; Ito and Matsuzaki, 1990), as well as to other prominent natural phenomena, has provided new guidelines for research into the process by which individual earthquakes are generated. For nearly a century the idea underlying such research has been the elastic rebound hypothesis of Reid (1910). This was developed by Fedotov (1968) into the hypothesis of the seismic cycle, and further refined as the seismic gap hypothesis (e.g. McCann $e t$ al., 1979). A high degree of regularity in earthquake occurrence characterizes these ideas, and has been regarded as part of their attractiveness. With the advent of plate tectonics as the acknowledged driving force behind the earthquake phenomenon, regularity appeared to be supported by the nearconstancy of plate motion. In the meantime, however, the various types of regularity have proved difficult to substantiate. As an initially impressive example of the seismic gap hypothesis, a segment of the San Andreas Fault near Parkfield, California, appeared to produce earthquakes of characteristic magnitude $M \approx 6.0$, at intervals of about 22 years (Roeloffs and Langbein, 1994). In studies directed towards earthquake prediction, the concept of regular recurrence is known as the time-predictable model. At Parkfield, the latest earthquake was confidently expected in January $1988, \pm 5$ years. No such earthquake has occurred up to now, some 16 years later. A recent proposal (Stein, 2002), that the earthquake has been

Copy right (c) The Society of Geomagnetism and Earth, Planetary and Space Sciences (SGEPSS); The Seismological Society of Japan; The Volcanological Society of Japan; The Geodetic Society of Japan; The Japanese Society for Planetary Sciences; TERRAPUB. delayed because it will be larger, invokes what is known as the slip-predictable model, and amounts to abandoning the characteristic magnitude concept. This leaves only the concept of the fault segment as an earthquake source virtually isolated from its surroundings. But outside influences on any particular fault, including dynamic and static stress transfer from other earthquakes, are the subject of many recent research reports, and Parkfield may have been affected in this way (Murray and Segall, 2002). All three main features of the seismic gap hypothesis now appear to be unsatisfactory (Rong et al., 2003), and a new basis is needed for understanding the seismogenic process.

Plate tectonics can now be seen as a driving force that maintains the lithosphere in a state of SOC (Scholz, 1991). Regularity is not a feature of this state, and some authors have concluded that earthquake occurrence is random and unpredictable (Geller et al., 1997). To the contrary, an analogy has been proposed between earthquakes and phase transitions as critical phenomena (Rundle, 1989), with the implication that a large earthquake may be the culmination of an emergent but accelerating moment release (AMR). In statistical mechanics, this is attributed to a correlation process that evolves towards increasingly large wavelengths. Evidence of the AMR precursor developing over an area of diameter several times the major fault-length has been found in a number of cases (Jaumé and Sykes, 1999; Bowman et al., 1998).

A variety of models relate earthquakes, as an SOC phenomenon, to the stick-slip behaviour commonly observed in laboratory experiments on rocks. These include the springblock model (Burridge and Knopoff, 1967; Olami et al., 1992), the cellular automaton (Nakanishi, 1990), and the 


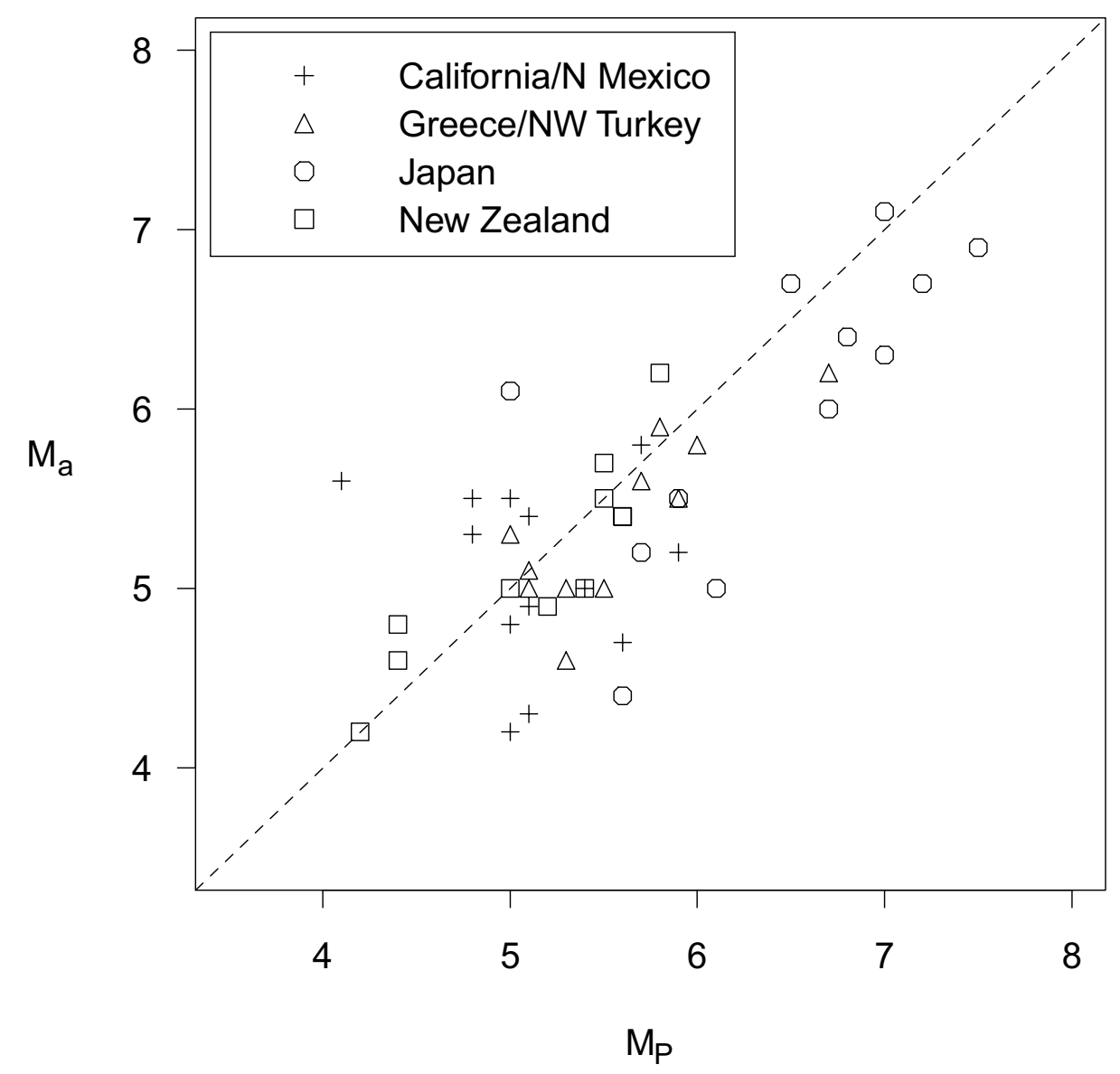

Fig. 1. Magnitude comparison between the fractal set of precursory earthquakes $\left(M_{P}\right)$ and the fractal set of aftershocks $\left(M_{a}\right)$. Dashed line is for $M_{a}=M_{P}$.

sand-pile (Bak et al., 1987). Such models are chiefly concerned with the way in which earthquakes recur on a particular fault. Models in general need to take account of transients, (Bernard, 2001), including changes that occur to the parameters as part of the process under consideration. With shear fracture, for example, the static coefficient of friction is appropriate before motion, but the dynamic coefficient applies immediately the motion starts. Since the dynamic coefficient is the smaller, the change tends to enhance the motion. The opposite occurs with the long-term seismogenic process, according to the model discussed in the present paper: an early transient inhibits the process and delays the earthquake.

The statistical mechanics approach has been taken recently to test whether the seismogenic lithosphere is in a critical or a subcritical state (Main and Al-Kindy, 2002; AlKindy and Main, 2003). The test was based on thermodynamical features of criticality, which showed differences between regions of different tectonic style, thus favouring subcriticality and suggesting that earthquakes are amenable to a degree of statistical predictability. A more empirical approach is taken in the present paper, with a view to determining to what extent the long-term seismogenic process displays the general features of SOC (i.e. fractality, scaling, hierarchy, and extreme sensitivity to initial conditions), whether the results are similar for different tectonic styles, and whether they support the possibility of long-range earthquake forecasting. Both approaches start from the universal fractality of the earthquake phenomenon.

\section{Fractality}

The Gutenberg-Richter relation describes the variation of frequency with magnitude of any sufficiently numerous set of earthquakes occurring within a given space-time envelope. This relation, which was foreshadowed by Ishimoto and Iida (1939) as a variation of frequency with felt intensity, is usually written

$$
\log _{10} N(M)=a-b M
$$

where $N(M)$ is the number of earthquakes in the set having magnitude $M$ or greater, $a$ is a measure of the size of the set, and $b$ is the variation parameter. By transforming from magnitude to energy or moment, the relation becomes a power law, and is thus typical of relations signifying fractality in a wide variety of phenomena. Kagan (1999) has studied global sets of earthquakes and found Eq. (1) to be of universal application, with the value of parameter $b$ close to unity.

The size of a set of earthquakes is of central importance to the present study of long-term seismogenesis. The $\Psi$ phenomenon (Evison and Rhoades, 2004) consists of a precursory set that has a higher magnitude level than that of the set occupying the prior period. The increase in magnitude level occurs suddenly, in a well-defined area around the future earthquake and its aftershocks, and at a time long beforehand (depending on the earthquake magnitude). The prior, precursory and aftershock earthquakes can all be considered 

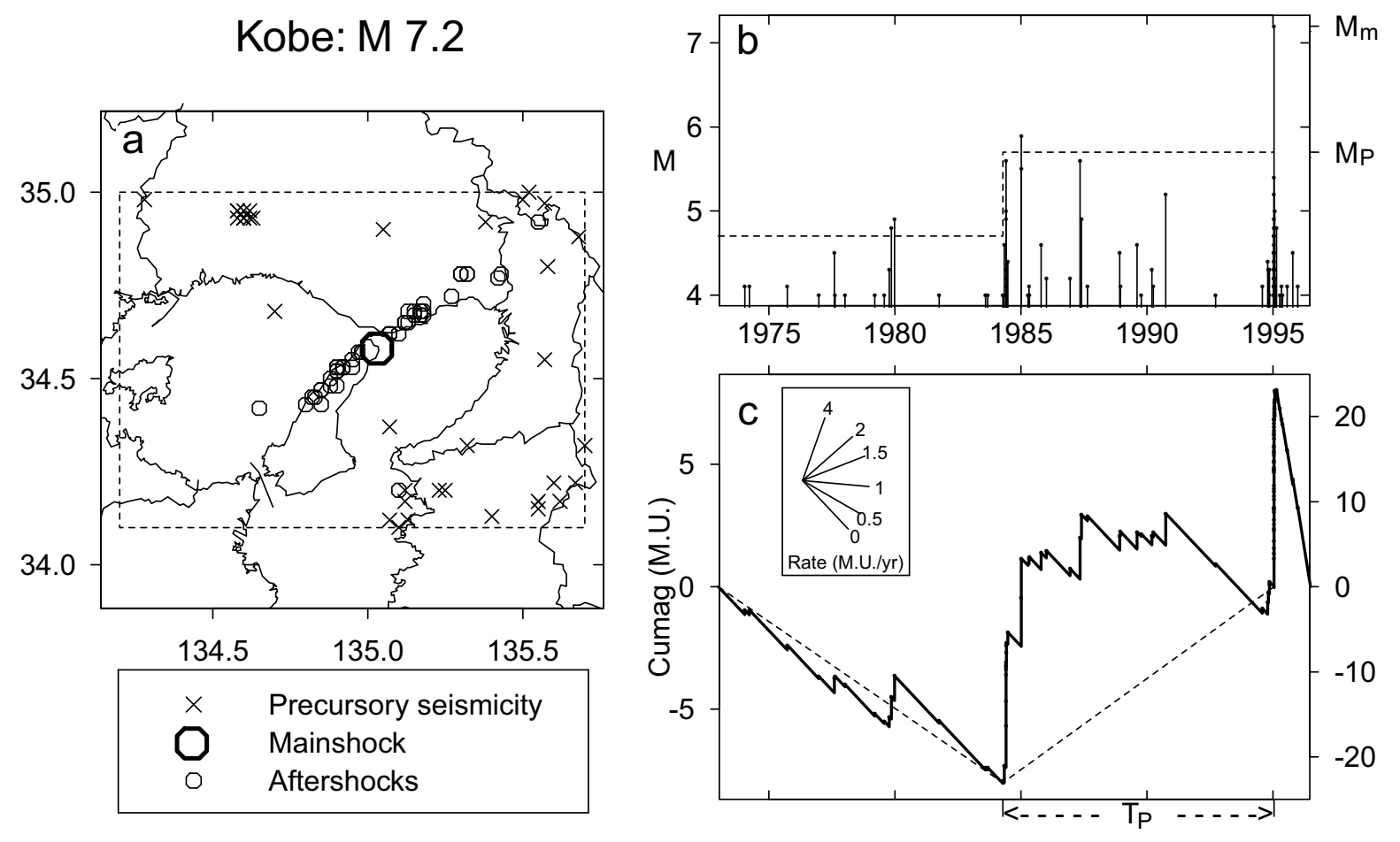

Fig. 2. $\Psi$-phenomenon: data and interpretation for the Kobe earthquake. (a) Seismogenic area $A_{P}$ (dashed lines), showing epicentres of the precursory and aftershock fractal sets. (b) Magnitudes vs time, showing the jump in magnitude level from prior to precursory fractal sets (dashed lines). (c) Cumag, showing the jump in seismicity rate from prior to precursory fractal sets (dashed lines).

as Gutenberg-Richter sets, although a set may be represented in the catalogue by only the few largest members. Since an apparent jump in seismicity may result from improved instrumentation, a rather high magnitude threshold is to be preferred for the purpose of identifying the $\Psi$-phenomenon, even though the number of earthquakes remaining is small. In these circumstances, the largest magnitude $M_{1}$ in a set can be used as a measure of level, but in view of the uncertainty of any single magnitude, a more robust quantity for this purpose, assuming that errors of estimation are random, is the average of the three largest magnitudes, $\left(M_{1}+M_{2}+M_{3}\right) / 3$. This measure is here called $M_{-}$for the prior period, $M_{P}$ for the precursory period, and $M_{a}$ for the aftershocks.

A remarkable feature of the $\Psi$-phenomenon is that the fractal set of precursory earthquakes has, on average, the same magnitude level as the aftershock set. The data plotted in Fig. 1 refer to 47 major earthquakes in the regions of California, Greece, Japan and New Zealand (Evison and Rhoades, 2004). The means and their standard errors are $M_{P}=5.57 \pm 0.11$ for the precursory sets, and $M_{a}=$ $5.41 \pm 0.10$ for the sets of aftershocks. According to these statistics, the mean precursory level and the mean aftershock level are indistinguishable. That they are broadly similar is indicated by the identity line in Fig. 1. The scatter of data here, as in other relations to be discussed below, is to be expected from the diversity of tectonic conditions included in the four regions under consideration. Possible systematic departures from the norm, for example the tendency in Fig. 1 for the Japan data to lie below the identity line, invite further study. The overall similarity appears to be a new result. It is not true of immediate foreshocks, which form part of the long-term precursory set but rarely contribute any of the larger magnitudes. The main result suggests that the longterm precursory seismicity (the $\Psi$-phenomenon) has a close physical connection with the aftershocks, and hence with the mainshock. Further support for such a connection is given in Section 3 below. An example of the jump in magnitude level from that of the prior set $\left(M_{-}\right)$to that of the precursory set $\left(M_{P}\right)$ is given in Fig. 2, which shows the seismicity associated with the long-term generation of the Hyogo-ken Nanbu (Kobe) earthquake of 1995 (M7.2). The source of data is the catalogue of the Japan Meteorological Agency. Figure 2(a) shows the epicentres of the precursory earthquakes, mainshock and aftershocks, for magnitudes $M \geq 4.0$. The area $\left(A_{P}\right)$ enclosed by the dashed lines is first chosen to contain the mainshock and aftershock epicentres, and then adjusted to optimize the precursory jump in magnitude level. The size of the area so obtained remains quite small-typically less than one-tenth the size of areas reported to be occupied by the AMR precursor (Bowman et al., 1998; Evison and Rhoades, 2002). Figure 2(b) is a magnitude vs time plot of the prior and precursory earthquakes, mainshock and aftershocks. The level of seismicity jumped from $M_{-}=4.7$ to $M_{P}=5.7$ on 1984.04 .14 , and the aftershock level was $M_{a}=$ 5.2. In Fig. 2(c), the data in Fig. 2(b) are plotted as a cumulative magnitude anomaly (cumag). This is a type of cusum (Page, 1954) designed to display the average rate of seismicity in a specified area between any two points in time. The cumag $C(t)$ is defined by:

$$
\begin{gathered}
C(t)=\sum_{t_{s} \leq t_{i} \leq t}\left(M_{i}-M_{c}+0.1\right)-k\left(t-t_{s}\right) \\
k=\sum_{t_{s} \leq t_{i} \leq t_{f}}\left(M_{i}-M_{c}+0.1\right) /\left(t_{f}-t_{s}\right)
\end{gathered}
$$




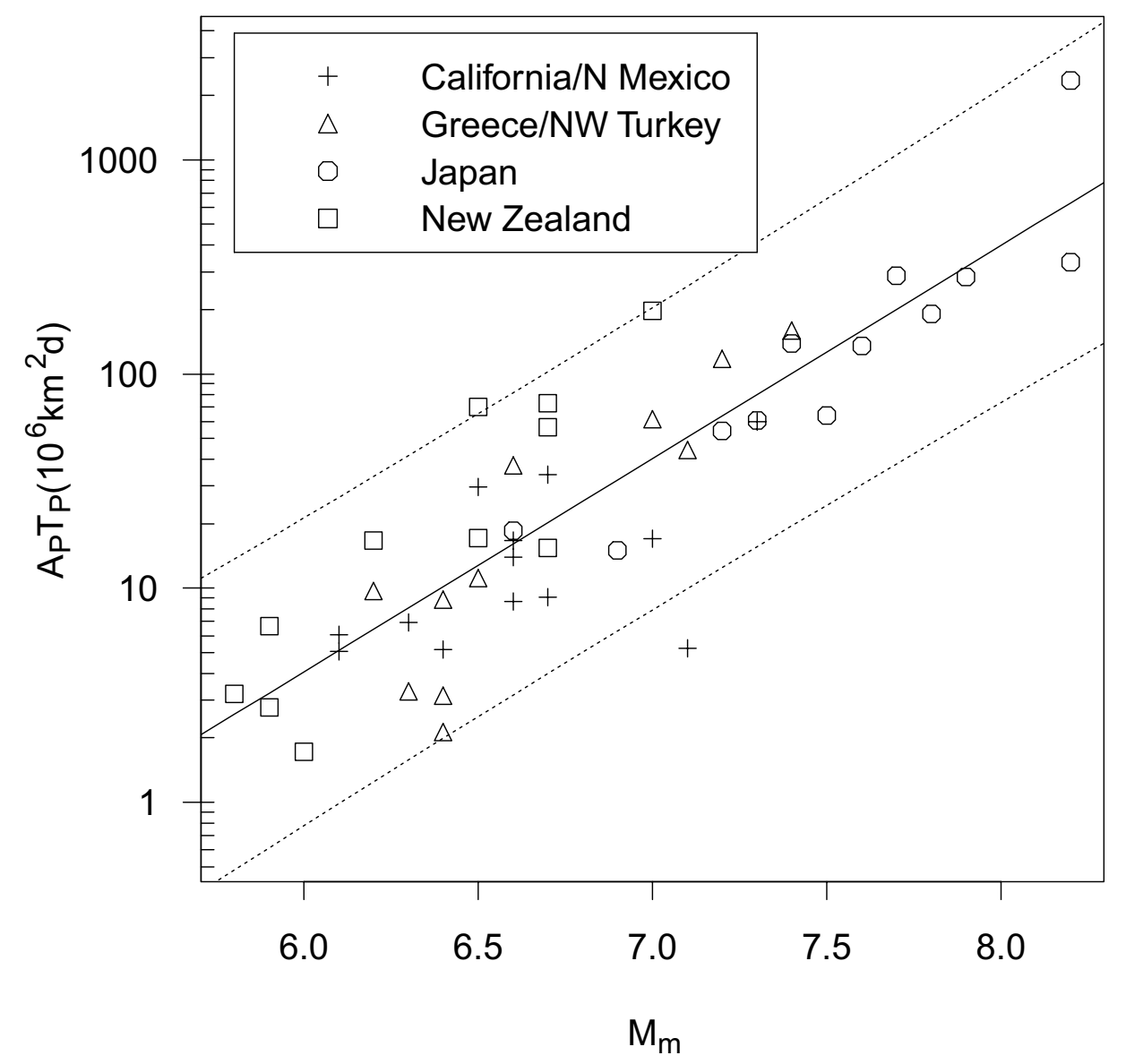

Fig. 3. Scaling relation between precursor space-time envelope $A_{P} T_{P}$ and mainshock magnitude $M_{m}$, for 47 major earthquakes. Dotted lines indicate $95 \%$ tolerance limits. See Eq. (4).

where $M_{i}$ is the magnitude and $t_{i}$ the time of the $i$ th earthquake, $M_{c}$ is the threshold magnitude, and $k$ is the average rate of magnitude accumulation between the starting time $t_{s}$ and the finishing time $t_{f}$. Accordingly, each small earthquake is represented by an upward jump equal to the amount by which the magnitude exceeds the baseline value, which is 0.1 below the threshold magnitude. The downward slope between successive earthquakes is equal and opposite to the sum of all the upward jumps, divided by the total time; thus, a given plot begins and ends at the value zero. Unlike most cusum graphs, the cumag abscissa is a linear scale of time. From Eqs. (2) and (3) it follows that the gradient of the line between any two points on the $C(t)$ curve is a measure of the average rate of earthquake activity during the corresponding time period. Gradients are translated into seismicity rates by means of a protractor, with seismicity rate expressed in magnitude units per year (M.U./yr). The onset of the precursory rate increase is indicated by the cumag minimum. At Kobe, this occurred on 1984.04.14. The duration of the precursory seismicity $\left(T_{P}\right)$ was 3930 days, and the average rate during this period exceeded that during an equal prior period by a factor of 4.8 .

Fractality is the property of earthquakes that draws attention to other general principles of self-organized criticality that can aid an understanding of the generation process of individual earthquakes. These are the principles of scaling, hierarchy, and extreme sensitivity to initial conditions.

\section{Scaling}

In a self-organized critical system, the principle of scaling states that the parameters of the system are similarly related over a wide range of sizes. This is true of the seismicity phenomena associated with long-term seismogenesis. The set of precursory earthquakes occupies a space-time envelope $A_{P} T_{P}$, as defined and illustrated with 47 examples by Evison and Rhoades (2004). In Fig. 2(a), $A_{P}$ is the epicentral area shown as a dashed-line rectangle, while in Fig. 2(c), $T_{P}$ is the time between the jump in seismicity level and the mainshock. $M_{P}$ is then the level of the set of earthquakes contained within $A_{P} T_{P}$. These two parameters $\left(M_{P}\right.$ and $\left.A_{P} T_{P}\right)$ are alternative specifiers of the Gutenberg-Richter set of precursory earthquakes. They are closely related to the mainshock magnitude $M_{m}$, as shown in Figs. 3 and 4 for the 47 major earthquakes. The regression equations are

$$
\begin{array}{cc}
\log _{10} A_{P} T_{P}=-2.36+1.00 M_{m} & R^{2}=75 \% \\
M_{P}=-1.86+1.09 M_{m} & R^{2}=71 \%
\end{array}
$$

Here the coefficients of $M_{m}$ are close to unity for data over the range $5.8 \leq M_{m} \leq 8.2$. The values of $R^{2}$, which give the percentages of variance explained, are high, considering that the data refer to a wide variety of tectonic environments, and are taken from four separate catalogues. Here again, possible systematic departures from the norm call for further study. In the meantime, when due allowance is made for the constant terms in Eqs. (4) and (5), the near-unity values of the 


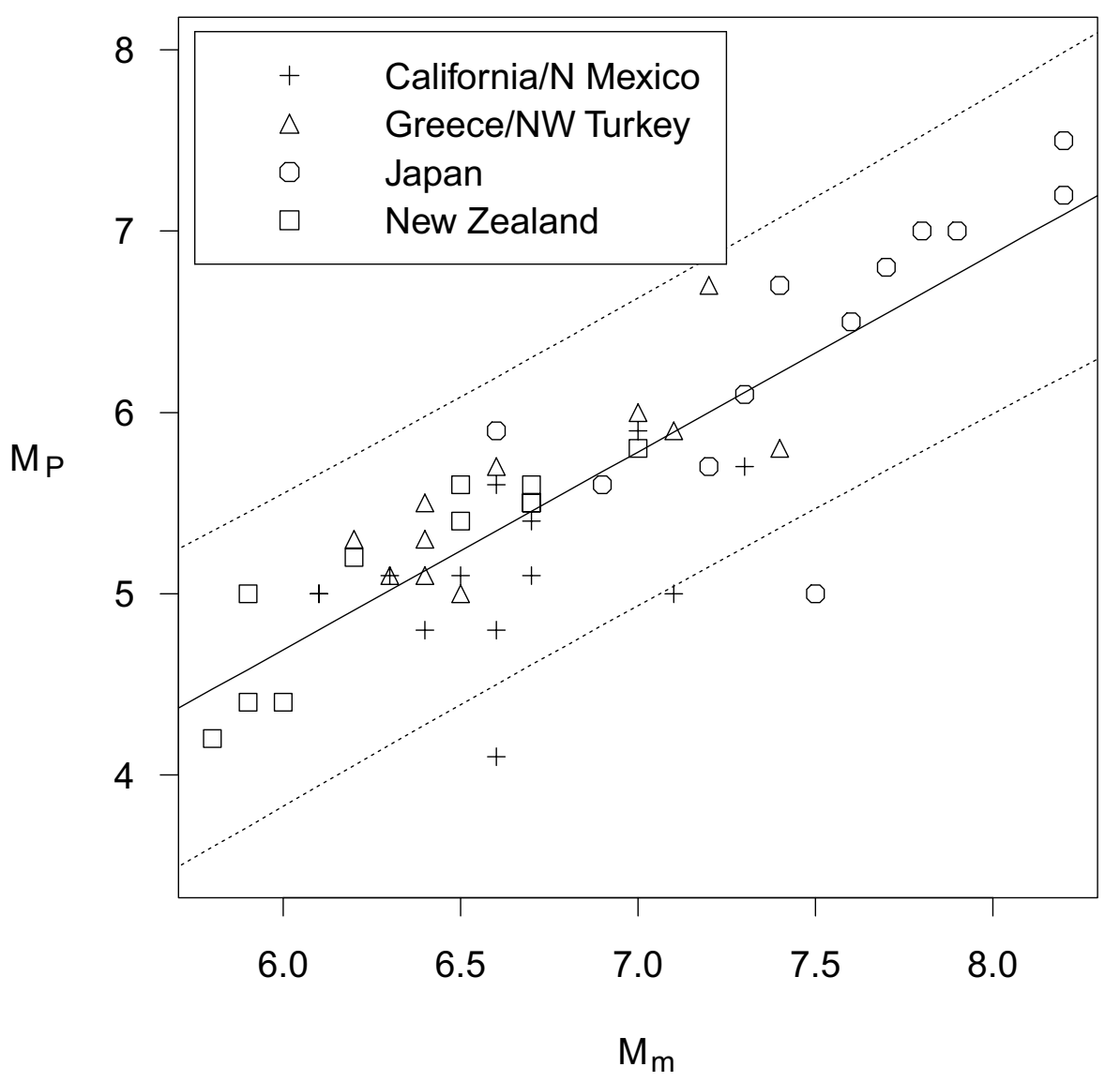

Fig. 4. Scaling relation between precursor magnitude $M_{P}$ and mainshock magnitude $M_{m}$, for 47 major earthquakes. Dotted lines indicate $95 \%$ tolerance limits. See Eq. (5).

coefficients of $M_{m}$ show that $\log _{10} A_{P} T_{P}, M_{P}$ and $M_{m}$ are near-equivalent measures of the same phenomenon: a major earthquake. In regressions of $\log _{10} A_{P}$ and $\log _{10} T_{P}$ separately on $M_{m}$ (Evison and Rhoades, 2004), the coefficients of $M_{m}$ are both close to 0.5 , indicating that area and time make, on average, comparable contributions, although the scatter of individual examples is rather wide.

The precursor magnitude $M_{P}$ can be regarded as a predictor of the mainshock magnitude $M_{m}$, the precursor time $T_{P}$, and the precursor area $A_{P}$. This has been taken as the basis of a stochastic forecasting model (Rhoades and Evison, 2004). In place of $M_{P}$, which as described above is the average of the three largest magnitudes in the precursory set of earthquakes, the model regards the magnitude of every earthquake in the catalogue (above the chosen threshold) as predictive. This is the EEPAS model (Every Earthquake a Precursor According to Scale). By thus setting aside the problem of identifying those earthquakes that are actually precursory, i.e. are members of a precursory set, the model accepts a weakening of the resultant forecast. Nevertheless, as a long-range estimator of earthquake occurrence, the model has been shown to perform much better than other available models (Rhoades and Evison, 2004). This lends credence to the $\Psi$-phenomenon as a predictor, and to the scaling relations derived from it.

The similarity in scale between the set of precursory earthquakes and the set of aftershocks (Fig. 1) suggests that the causes of both sets are also similar in scale. This has been incorporated in a three-stage faulting model of seismogenesis (Evison and Rhoades, 2001). The stages — crack formation, shear fracture and healing — are well known. The new feature of the model is to allow a time interval, which scales with the earthquake magnitude, between crack formation and shear fracture. This is the precursor time $T_{P}$ discussed above. The seismogenic process starts with the formation of a major crack, which is taken to have the same scale as the main shear fracture and the resultant mainshock. The role of the major crack is clarified by calling it the maincrack. It immediately generates a set of minor cracks (called aftercracks), in much the same way that a mainshock generates aftershocks. This is the start of the transient mentioned earlier, which has the effect of inhibiting the seismogenic process, and thus delaying the occurrence of the earthquake. Meanwhile, the transient provides, in the $\Psi$-phenomenon, evidence as to the future earthquake's location, time and magnitude. The delay is attributed to the Mogi effect. Mogi (1963) showed experimentally that large earthquakes occur when the medium and stress-field are relatively uniform, and small earthquakes when they are relatively non-uniform. This result can be expressed in terms of scaling: earthquakes require a degree of uniformity on their own scale. The aftercracks render the medium and stress-field non-uniform on the scale of the maincrack. Uniformity on this scale is only re-established by the fracturing and subsequent healing of the aftercracks. This occupies the time interval $T_{P}$, after which the shear fracture is enabled to proceed. There is some similarity between the 


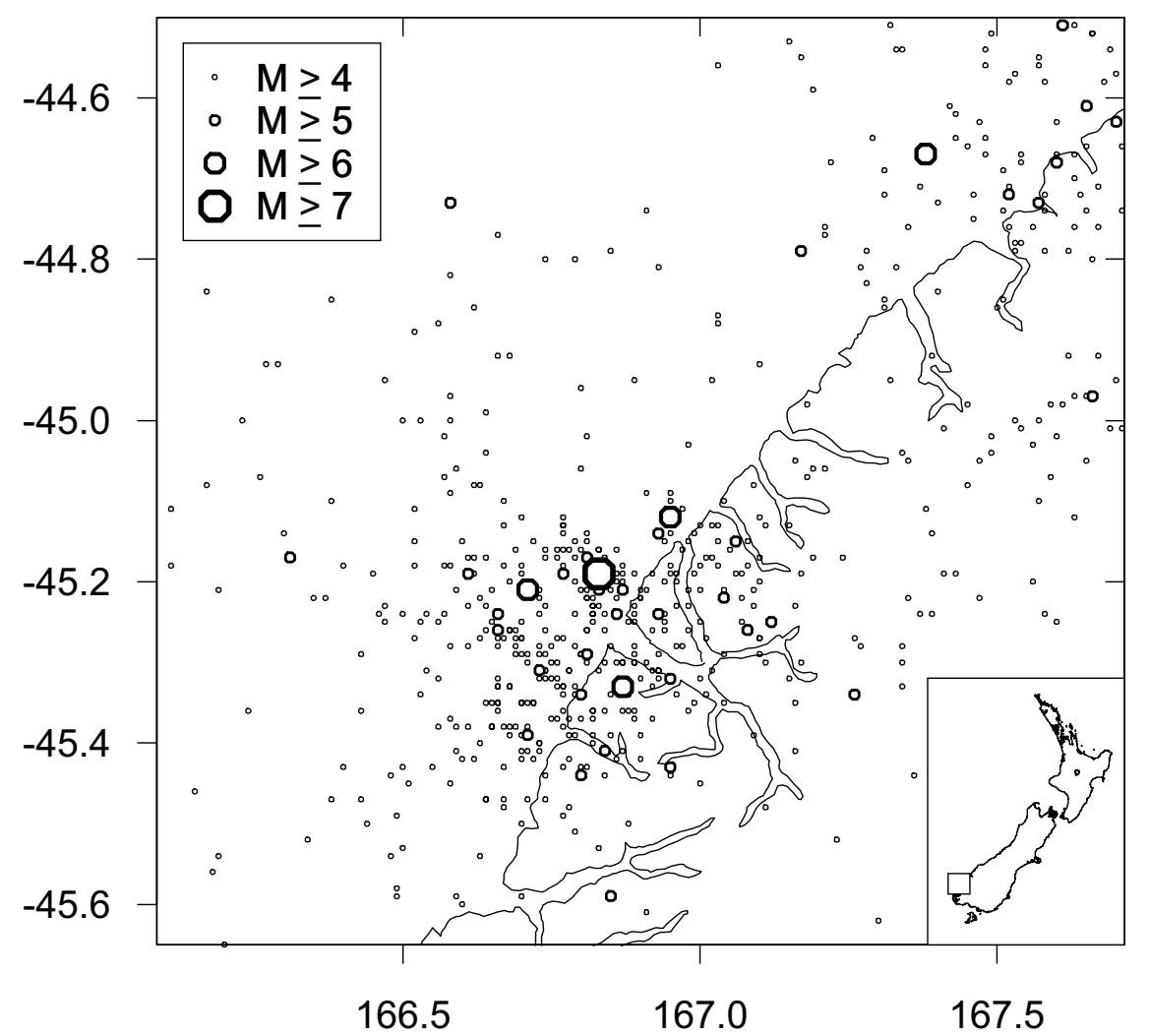

Fig. 5. Epicentre map, Fiordland, New Zealand, 1964-2003, $h \leq 33$ km.

Mogi effect and the effect to which accelerated moment release (AMR) is attributed. In both, the earthquake is delayed until appropriate conditions have evolved at the scale of the causative fault. In particular examples, however, a comparison between $\Psi$ and AMR is difficult to make, especially because of the widely different areas involved, as mentioned above. Nor can the times occupied be readily compared, since although $\Psi$ starts suddenly, AMR is emergent.

In the lead-up to a major earthquake, the three-stage faulting model can be both compared and contrasted with the well-known asperity model (Kanamori, 1981). Both models attribute the delay in major fracture on a fault to some kind of non-uniformity. In the asperity model, the strength of the fault is non-uniform, while the ambient stress can be assumed uniform. In the three-stage faulting model, the ambient stress is non-uniform, while the strength can be assumed uniform. In the asperity model, aseismic slip may occur in the low-strength areas around the asperities (Iio et al., 2003). In the three-stage faulting model, aseismic slip may occur in the areas of higher stress, and also at the start of the seismogenic process, as will be discussed below. In the asperity model, major dislocation occurs when the asperities fracture. In the three-stage faulting model, major dislocation occurs when the applied stress becomes uniform and the entire fault fractures. It is not clear whether available kinds of observations, including GPS, are capable of distinguishing between these models. In terms of stress, the chief innovation in the three-stage faulting model is that the seismogenic process involves an increasing uniformity of the stress-field, not an increasing level of stress.

No direct evidence of the postulated crack formation has so far been reported in association with the observed examples of the $\Psi$-phenomenon. The type of evidence needed may be represented by recent observations of aseismic slip. Creep-meters installed on several faults in California have recorded occurrences of aseismic slip (Bodin et al., 1994). The method of interferometric synthetic aperture radar has also been used to search for aseismic slip (Mellors et al., 2002). However, most studies aimed at detecting precursors to the nucleation of large earthquakes concentrate on the immediately preceding period, it being assumed that crack formation immediately precedes fracture. But several otherwise disparate studies point to the plausibility of our proposal that crack formation long precedes fracture, and is triggered by seismic waves. Waves from many earthquakes in Southern California are known to have triggered other earthquakes (Gomberg et al., 2001). Examples of earthquake-triggered aseismic slip have also been widely reported (Bodin et al., 1994; Rymer et al., 2002). And according to some models, crack formation involves aseismic slip (Scholz, 1990).

Scaling within the three-stage faulting model offers an explanation of a secondary feature of the set of precursory earthquakes compared to the set of aftershocks. This is that although the two magnitude levels are similar, the precursory set usually contains fewer earthquakes (above threshold) than the aftershocks. The explanation is that the long duration of the precursory period allows some of the precursory aftercracks to heal without fracturing. This applies especially to the smaller aftercracks, since, under scaling, the healing time can be expected to scale with magnitude. With the Landers (California) fault system, it appears that the healing time after the 1992 earthquake (M 7.3) was about $10 \mathrm{yr}$ 

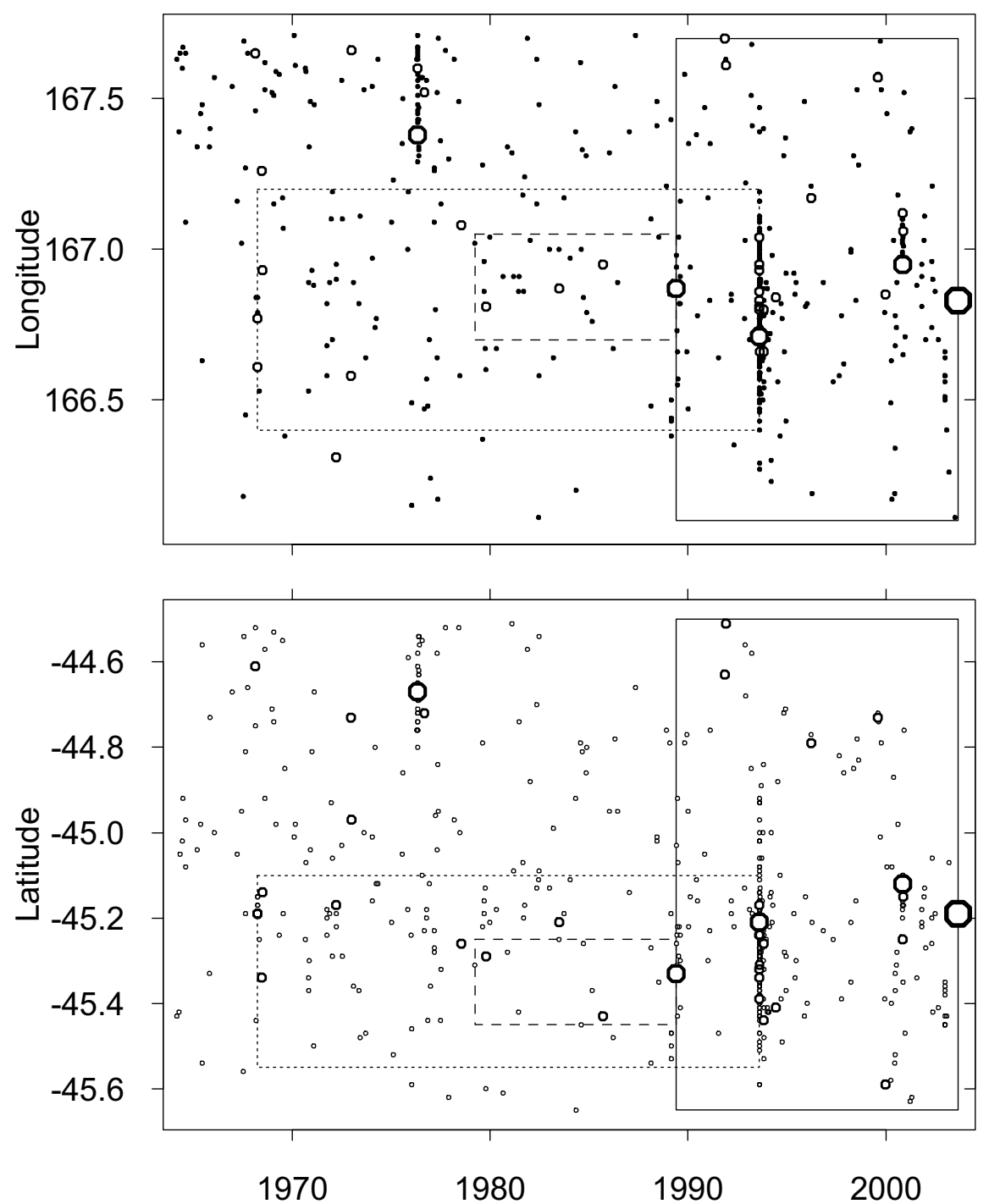

Time

Fig. 6. Hierarchical analysis: space-time distribution of earthquakes in Fig. 5. Boxes show precursory space-time envelopes for Doubtful Sound earthquake (dashed lines), Secretary Island earthquake (dotted lines) and Fiordland earthquake (solid lines).

(Vidale and Li, 2003). This compares with a precursor time of $12.6 \mathrm{yr}$ for this earthquake (Evison and Rhoades, 2002), suggesting that the two time intervals may be roughly similar for a given mainshock magnitude.

\section{Hierarchy}

On the principle of hierarchy, fractals on different scales can overlap in space and time. A systematic example of this principle is the fractal tree (Turcotte, 1997). The inclusion of a small fractal within a larger is sometimes called nesting (Hergarten, 2002). An implication of this principle is that an individual earthquake may occupy two or more roles simultaneously. A well-known example, first pointed out by Utsu (1970), long before the advent of SOC in seismology, is the aftershock that produces its own aftershocks, and thus, on its own scale, can be called a mainshock. Such labels refer to the relation between one earthquake and another, and the appropriate label is often a matter of scale.

Two examples of the nesting of long-term seismogenic processes have been discussed previously (Evison and Rhoades, 2004). Off East Cape, New Zealand, during 19791995, a process that culminated in a M5.9 mainshock occurred within the precursory area, and early in the precursory period, of a process that culminated in a $M 7.0$ mainshock. Likewise, in California, the M6.1 (1992) Joshua Tree process occurred within the precursory area of the $M 7.3$ (1992) Landers process, but in the latter part of the Landers precursory period. In both these examples, the mainshock of the smaller-scale process was among the precursory earthquakes in the larger-scale process.

Hierarchy of a more complex nature is displayed in the recent seismicity of the Fiordland region of New Zealand. Four shallow earthquakes with magnitudes 6.1, 6.2, 6.7 and 7.0 occurred close together in Fiordland between 1989 and 2003. The four epicentres were located within a radius of about 13 $\mathrm{km}$. This is highly unusual. In the whole of New Zealand, earthquakes of magnitude 6.0 or greater occur about once per year on average. Yet in this very small part of Fiordland, four 

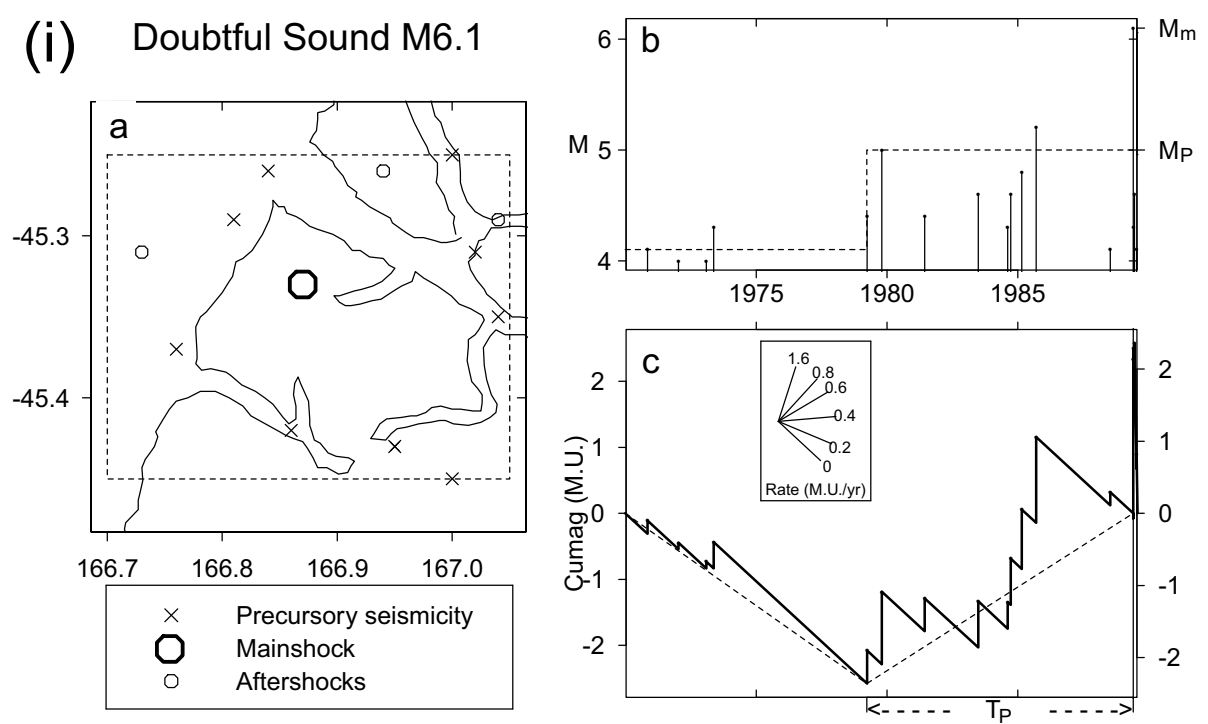

\section{(ii) Secretary Island M6.7}
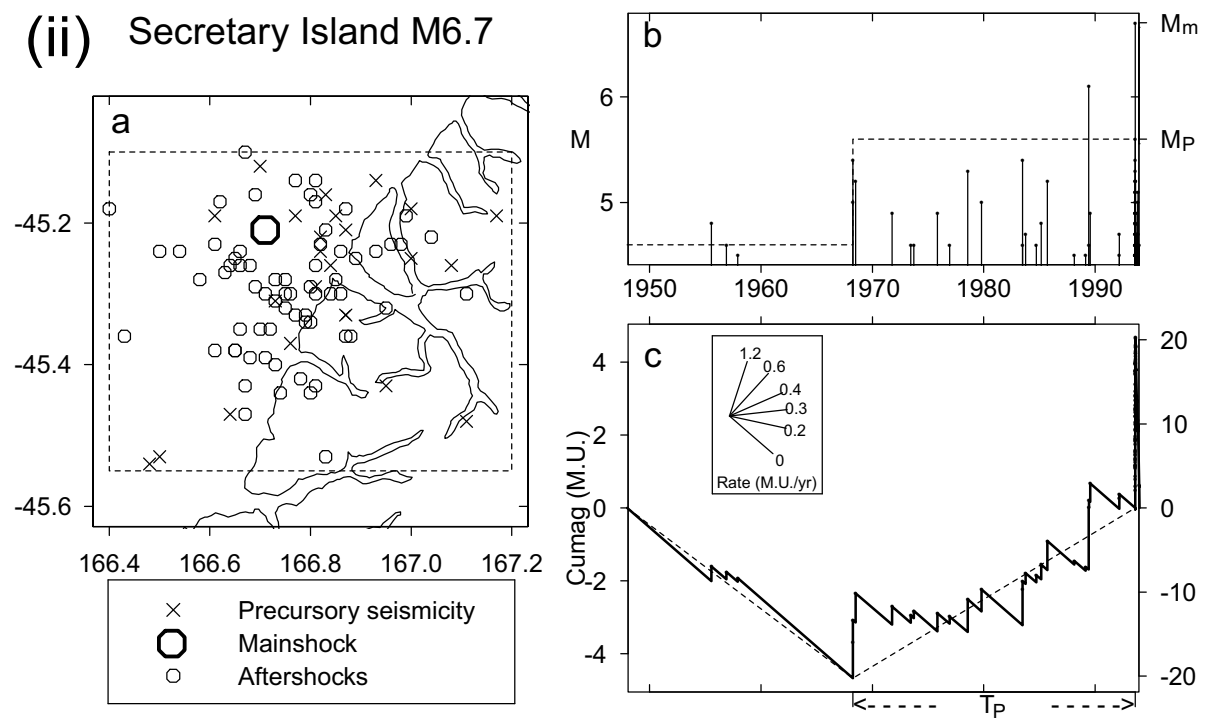

(iii) Fiordland M7.0
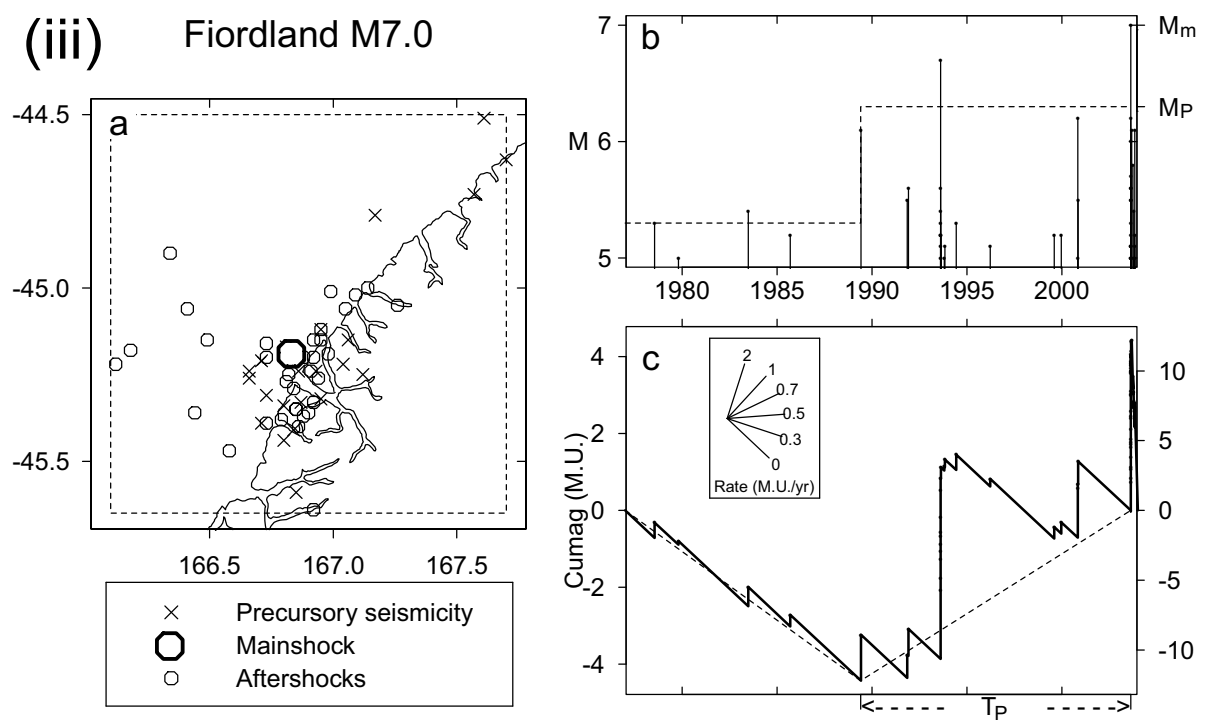

Fig. 7. $\Psi$-phenomenon: data and interpretation for (i) Doubtful Sound earthquake, (ii) Secretary Island earthquake, (iii) Fiordland earthquake. (a) Seismogenic area $A_{P}$ (dashed lines), showing epicentres of the precursory and aftershock fractal sets. (b) Magnitudes vs time, showing the jump in magnitude level from prior to precursory fractal sets (dashed lines). (c) Cumag, showing the jump in seismicity rate from prior to precursory fractal sets (dashed lines). 
Table 1. Seismogenesis: demarcation statistics.

\begin{tabular}{lccccccc}
\hline Locality & Start & $M_{c}$ & Latitude & Longitude & \multicolumn{2}{c}{ Scale increase } & Onset \\
& date & & & & Rate & $M$ & date \\
\hline Doubtful Sd & 1970.01 .01 & 4.0 & S45.25-45.45 & E166.70-167.05 & 7.15 & 0.9 & 1979.03 .27 \\
Secretary I & 1948.01 .01 & 4.5 & S45.10-45.55 & E166.40-167.20 & 13.0 & 1.0 & 1968.04 .03 \\
Fiordland & 1977.01 .01 & 5.0 & S44.50-45.65 & E166.10-167.70 & 7.38 & 1.0 & 1989.05 .31 \\
\hline
\end{tabular}

Table 2. Seismogenesis: scaling statistics.

\begin{tabular}{lcccccccc}
\hline Locality & \multicolumn{3}{c}{ Precursor parameters } & \multicolumn{5}{c}{ Mainshock event parameters } \\
& $M_{P}$ & $T_{P}(\mathrm{~d})$ & $A_{P}\left(10^{3} \mathrm{~km}^{2}\right)$ & Date & Latitude & Longitude & $M_{m}$ & $M_{a}$ \\
\hline Doubtful Sd & 5.0 & 3718 & 0.61 & 1989.05 .31 & S45.33 & E166.87 & 6.1 & 4.3 \\
Secretary I & 5.6 & 9260 & 3.13 & 1993.08 .10 & S45.21 & E166.71 & 6.7 & 5.4 \\
Fiordland & 6.3 & 6291 & 20.30 & 2003.08 .21 & S45.19 & E166.83 & 7.0 & 6.1 \\
\hline
\end{tabular}

such earthquakes occurred in 15 years. The shallow seismicity of the area around these earthquakes and their aftershocks, for the period from 1964 until the time of the M7.0 mainshock, is shown in Fig. 5. The data are taken from the Seismological Observatory Bulletins of the Institute of Geological and Nuclear Sciences, New Zealand.

By considering a hierarchy of scales, each of the M6.1, 6.7 and 7.1 earthquakes is found to display the precursory scale increase, and the three seismogenic processes can be separately identified. The space-time relations are shown diagrammatically in Fig. 6. As a typical example of nesting, the space-time envelope of the $M 6.1$ earthquake is completely enclosed in that of the $M 6.7$ earthquake. Thus the $M 6.1$ precursors, mainshock and aftershocks are all part of the $M 6.7$ precursor. A more limited relation links the $M 6.1$ and $M 7.0$ earthquakes. The former marks the onset of the $\Psi$ phenomenon for the latter; the seismogenic area of the $M 6.1$ earthquake lies within that of the $M 7.0$ earthquake, but the time intervals abut. An intermediate relation links the $M 6.7$ and M7.0 earthquakes. Again the seismogenic area of the former lies within that of the latter, while the two times overlap, so that the later earthquakes in the $M 6.7$ precursor are among the earlier earthquakes in the $M 7.0$ precursor. In the model, some of the cracks that contribute to the $\Psi$-precursor of a particular mainshock may have existed before the formation of the relevant maincrack. For example, the crack that fractured to produce the $M 6.7$ earthquake will have been formed in 1968, not 1989. Also contributing to the $M 7.0$ precursor was the $M 6.2$ earthquake of 2000.11.01, together with its aftershocks. This earthquake did not itself display a $\Psi$-precursor; under the model, it resulted simply from the fracture of an aftercrack generated by the "M7.0" maincrack.

Details of the $\Psi$-phenomenon for the $M 6.1,6.7$ and 7.0 earthquakes are shown in Fig. 7. These examples are broadly similar to one another, and also to the 47 examples previously published (Evison and Rhoades, 2004). (The previous solution for the M6.7 earthquake has now been somewhat improved by reducing the area and increasing the prior time.) The parameter values are listed in Tables 1 and 2. They accord well with the $M_{a}$ versus $M_{P}$ correlation in Fig. 1, and with the regression data in Figs. 3 and 4 . Thus by the hierarchy principle a tight cluster of large earthquakes has been separated out into three typical long-range generation processes.

\section{Extreme Sensitivity to Initial Conditions}

A further, highly unusual relation between two large earthquakes confirms, by an a fortiori argument, the SOC principle of extreme sensitivity to initial conditions: that a major event can be initiated by a very small effect. In meteorology this is known as the butterfly effect: a butterfly flapping its wings can initiate an air-pressure disturbance that culminates in a tropical cyclone. By analogy, in seismology we can picture a grasshopper effect: a grasshopper jumping can initiate a ground-pressure disturbance that culminates in a major earthquake. More prosaically, considering the high frequency of very small earthquakes indicated by Eq. (1), such earthquakes provide an abundant source of potential initiating effects. When all relevant conditions are favourable, an event can be initiated by a microearthquake. It is widely accepted that mainshocks are triggered in this way, unless, as may sometimes occur, by an observed foreshock. Indeed, a wide variety of small disturbances have been proposed as possible triggers of major earthquakes. Under SOC there are many possibilities, and one cannot expect to attribute triggering to any systematic cause, nor to identify the trigger in most cases. Likewise, in the three-stage faulting model, a very small earthquake (or other disturbance) may start the long-term seismogenic process, by nucleating the formation of the major crack (maincrack). Then the suddenness of the jump in seismicity that marks the onset of the $\Psi$-phenomenon suggests that this onset occurs shortly after the maincrack event.

The proposal that an event can be nucleated by a very small earthquake (or other low-level disturbance) implies, $a$ fortiori, that a large earthquake can also perform this function, under the usual condition that all relevant conditions are favourable. Out of the more than 60 major earthquakes so far found to display the $\Psi$-phenomenon, in only one case can the nucleation of a maincrack be attributed to a nearby earthquake of similar scale. The case is that of the Hector Mine earthquake $(M 7.1,1999)$ in California, for which the maincrack nucleation can be attributed to the Landers earthquake $(M 7.3,1992)$. These two large earthquakes occurred 
Table 3. Landers to Hector Mine interaction: catalogue data $(M \geq 3.5)$.

\begin{tabular}{|c|c|c|c|c|}
\hline Earthquake & $\begin{array}{c}\text { Time } \\
\mathrm{y} \cdot \mathrm{m} \cdot \mathrm{d} \cdot \mathrm{h} \cdot \mathrm{m}\end{array}$ & Lat. $\mathrm{N}$ & Long. W & $M$ \\
\hline Landers & 1992.06 .28 .11 .57 & 34.20 & 116.44 & 7.30 \\
\hline HM precursor & 1992.06 .28 .14 .32 & 34.62 & 116.44 & 3.60 \\
\hline ، & 1992.06 .29 .12 .54 & 34.54 & 116.22 & 3.50 \\
\hline “ & 1992.06 .30 .08 .57 & 34.57 & 116.41 & 3.60 \\
\hline “ & 1992.07 .05 .10 .36 & 34.62 & 116.34 & 3.50 \\
\hline “ & 1992.07 .05 .21 .18 & 34.58 & 116.32 & 5.40 \\
\hline “ & 1992.07 .05 .22 .08 & 34.59 & 116.30 & 3.80 \\
\hline “ & 1992.07 .05 .22 .33 & 34.59 & 116.30 & 4.40 \\
\hline “ & 1992.07 .05 .23 .11 & 34.59 & 116.29 & 3.50 \\
\hline “ & 1992.07 .06 .04 .49 & 34.58 & 116.31 & 3.50 \\
\hline “ & 1992.07 .08 .02 .23 & 34.58 & 116.34 & 4.90 \\
\hline “ & 1992.07 .08 .08 .05 & 34.60 & 116.35 & 4.30 \\
\hline " & 1992.07 .24 .11 .06 & 34.57 & 116.43 & 3.80 \\
\hline “ & 1992.08 .20 .12 .36 & 34.57 & 116.31 & 4.20 \\
\hline “ & 1992.09 .01 .12 .17 & 34.60 & 116.32 & 3.90 \\
\hline “ & 1992.09 .03 .06 .17 & 34.37 & 116.44 & 3.80 \\
\hline “ & 1992.09 .18 .04 .43 & 34.86 & 116.32 & 4.00 \\
\hline “ & 1994.01 .11 .04 .20 & 34.80 & 116.29 & 4.70 \\
\hline “ & 1994.08 .28 .12 .20 & 34.79 & 116.30 & 3.70 \\
\hline “ & 1994.09 .26 .08 .58 & 34.80 & 116.30 & 3.50 \\
\hline “ & 1996.08 .14 .03 .05 & 34.60 & 116.28 & 4.30 \\
\hline “ & 1996.10 .20 .00 .17 & 34.60 & 116.28 & 4.09 \\
\hline “ & 1999.10 .16 .02 .41 & 34.59 & 116.27 & 3.76 \\
\hline Hector Mine & 1999.10 .16 .09 .46 & 34.59 & 116.27 & 7.10 \\
\hline
\end{tabular}

Note: $M$ is $M_{W}$ for Landers and Hector Mine, and $M_{L}$ for the Hector Mine (HM) precursors.

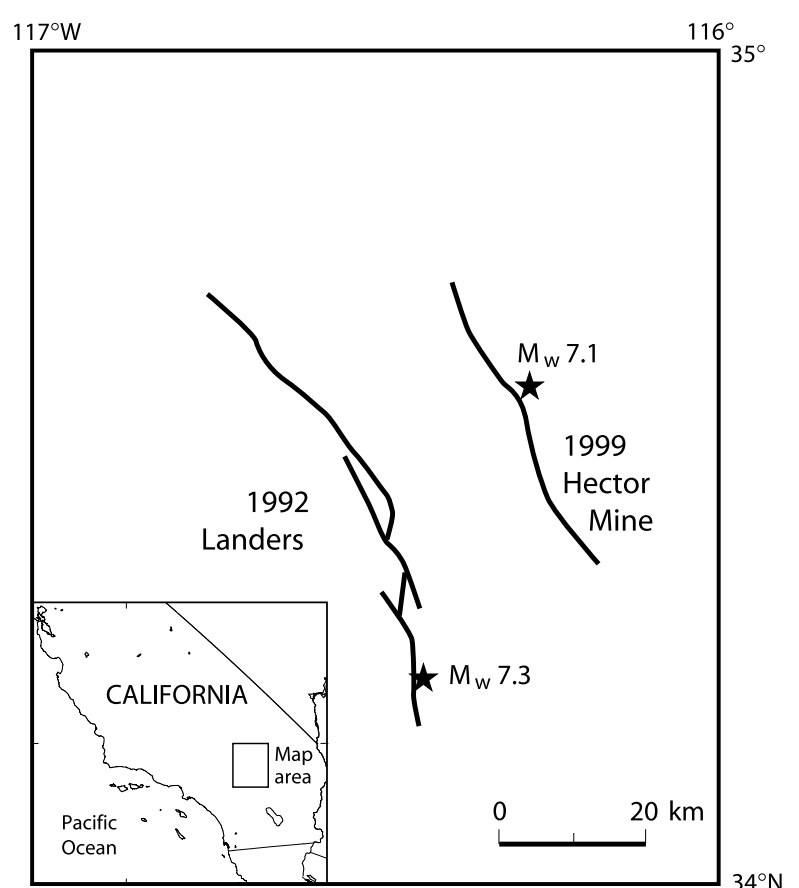

Fig. 8. Locality map showing Landers and Hector Mine rupture zones and mainshock epicentres (stars). in the Eastern California Shear Zone, on fault systems separated by $20-25 \mathrm{~km}$ (Fig. 8). As shown in a detailed study of twelve major earthquakes in California and northern Mexico, the Landers earthquake and the onset of the Hector Mine $\Psi$-phenomenon both occurred on the same day: 1992.06.28 (Evison and Rhoades, 2002, Table 1). No comparable example appears in the lists of large earthquakes studied in four different regions of the world (Evison and Rhoades, 2004).

Closer examination shows that the Landers earthquake preceded the jump in seismicity in the Hector Mine area by about $2 \mathrm{hr} 35 \mathrm{~min}$. The $\Psi$-phenomenon for Hector Mine is shown in Fig. 9. (The data-base is the CNSS Worldwide Earthquake Catalog, 1954-2000.) The times and locations of the Landers mainshock, and of the Hector Mine precursory earthquakes and mainshock, are shown in Table 3. The brief delay of $2 \mathrm{hr} 35$ min may well have been enough to allow the triggering and formation of the maincrack, the formation of at least a number of aftercracks, and the onset of the Hector Mine precursor. This is reasonable in terms of the model, in which the maincrack/aftercrack process is analogous to the mainshock/aftershock process. The parameter values of the Hector Mine $\Psi$-phenomenon were not unusual for an earthquake of that magnitude (Evison and Rhoades, 2004). The only value that fell outside the $95 \%$ tolerance limits was 

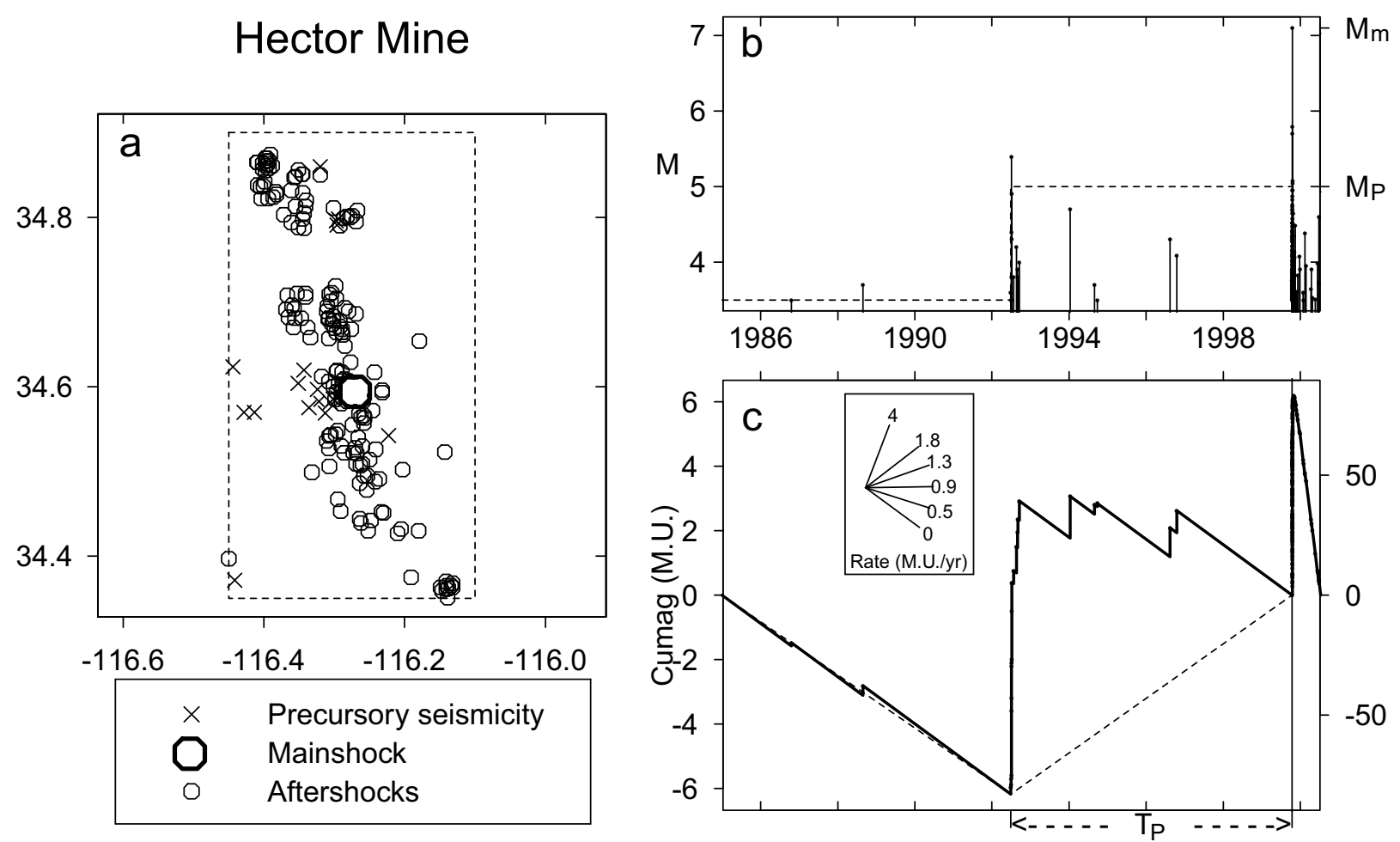

Fig. 9. $\Psi$-phenomenon: data and interpretation for the Hector Mine earthquake. (a) Seismogenic area $A_{P}$ (dashed lines), showing epicentres of precursory and aftershock fractal sets. (b) Magnitudes vs time, showing the jump in magnitude level from prior to precursory fractal sets (dashed lines). (c) Cumag, showing the jump in seismicity rate from prior to precursory fractal sets (dashed lines).

the area $A_{P}$. The otherwise typical values suggest that, apart from nucleation, the Hector Mine generation process was not greatly influenced by the Landers event.

Much weight has been given in the literature to the fact that the Landers and Hector Mine earthquakes occurred only 7 years apart, when the statistical average recurrence interval for $M \geq 7.0$ earthquakes in the Eastern California Shear Zone has been variously estimated as between 1500 and 50,000 years (Price and Burgmann, 2002). Under selforganized criticality, the average recurrence interval is irrelevant to the occurrence of any particular earthquake, and, as already mentioned, short-term nucleation is normally attributable to very small effects. Many authors, using other models, have sought some causal connection between the Landers and Hector Mine mainshocks. If such a connection is plausible after a 7 years' delay, then the present proposal is so much the more plausible after $2 \mathrm{hr} 35 \mathrm{~min}$.

Triggering after a 7 years' delay has been difficult to account for. It has been suggested (Mellors et al., 2002) that triggering by delayed stress transfer may have involved not only the Landers mainshock but the Pisgah earthquake of 1992.07.05.21.18, M5.40 (Table 3), since, although the Pisgah earthquake was much smaller than Landers, its epicentre was very much closer to the eventual Hector Mine epicentre. Alternatively, the triggering may have been achieved by a very late Landers aftershock, i.e. an aftershock of an aftershock, as has been suggested by Felzer et al. (2002). A study using a combination of space geodesy, boundary element modelling, and computer modelling of time-dependent fault friction, concluded that the delay could have been anything from 0 to 40 years (Price and Burgmann, 2002). A viscoelastic model calibrated by geodetic data showed that viscoelastic relaxation after the Landers earthquake would have produced a transient stress increase of about $0.7 \mathrm{Mpa}$ on the Hector Mine rupture surface, which was enough to have contributed to the earthquake (Pollitz and Sacks, 2002). But even the possibility of stress triggering is open to question in this case. A simple approach in which static dislocations in an elastic half-space accompanied the Landers earthquake and aftershocks indicated stress changes ranging from -0.3 to $+0.3 \mathrm{Mpa}-$ an inconclusive result (Harris and Simpson, 2002).

The Landers/Hector Mine interaction gives us, for the first time, evidence of the likely time-scale of events at the start of the seismogenic process. Under the three-stage faulting model, the simplest explanation of the $2 \mathrm{hr} 35 \mathrm{~min}$ delay between the Landers earthquake and the Hector Mine process is that this brief time interval was sufficient for the Hector Mine maincrack to be triggered dynamically by the Landers earthquake, then for at least some aftercracks to form, and finally for the first resulting $M \geq 3.5$ precursory earthquake to occur. Whether crack formation on the Hector Mine fault system was accompanied by aseismic slip is an open question, since no creep meters were operational there at the time of the Landers earthquake (Bodin et al., 1994), and the search for aseismic slip by the method of synthetic aperture radar only began 5 days after (Mellors et al., 2002).

\section{Conclusion}

This study shows that the complexities of seismicity can be reduced to relatively simple patterns by applying the principles of SOC. Fractality, scaling, hierarchy, and extreme 
sensitivity to initial conditions provide a rich set of analytical concepts. SOC has accordingly been included as an integral factor in the three-stage faulting model of longterm seismogenesis, and, as a result, the interpretation of the $\Psi$-phenomenon as a precursor to moderate-to-large shallow earthquakes has been greatly facilitated. The further study of seismogenesis, and its application to earthquake forecasting, can be expected to benefit from a continued reliance on the principles of SOC.

Acknowledgments. This work was supported in part by the New Zealand Foundation for Research, Science and Technology under Contract No. CO5X0006. The first author acknowledges facilities provided under an Honorary Fellowship at Victoria University of Wellington.

\section{References}

Al-Kindy, F. H. and I. G. Main, Testing self-organized criticality in the crust using entropy: a regionalized study of the CMT global earthquake catalogue, J. Geophys. Res., 108(B11), 2521, doi:10.1029/2002JB002230, 2003.

Bak, P. and C. Tang, Earthquakes as a self-organized critical phenomenon, J. Geophys. Res., 94, 15635-15637, 1989.

Bak, P., C. Tang, and K. Wiesenfeld, Self-organized criticality. An explanation of 1/f noise, Phys. Rev. Lett., 59, 381-384, 1987.

Bernard, P., From the search of 'precursors' to the research on 'crustal transients', Tectonophysics, 338, 225-232, 2001.

Bodin, P., R. Bilham, J. Behr, J. Gomberg, and K. W. Hudnut, Slip triggered on Southern California faults by the 1992 Joshua Tree, Landers, and Big Bear earthquakes, Bull. Seismol. Soc. Am., 84, 806-816, 1994.

Bowman, D. D., G. Ouillon, C. G. Sammis, A. Sornette, and D. Sornette, An observational test of the critical earthquake concept, J. Geophys. Res., 103, 24,359-24,372, 1998.

Burridge, R. and L. Knopoff, Model and theoretical seismicity, Bull. Seismol. Soc. Am., 57, 341-371, 1967.

Evison, F. F. and D. A. Rhoades, Model of long-term seismogenesis, Annali di Geofisica, 44, 81-93, 2001.

Evison, F. F. and D. A. Rhoades, Precursory scale increase and long-term seismogenesis in California and northern Mexico, Annals of Geophysics, 45, 479-495, 2002.

Evison, F. F. and D. A. Rhoades, Demarcation and scaling of long-term seismogenesis, Pure Appl. Geophys., 161, 21-45, 2004.

Fedotov, S. A., The seismic cycle, quantitative seismic zoning, and longterm seismic forecasting, in Seismic Zoning in the USSR, edited by S. V. Medvedev, pp. 133-166, Izdatel'stvo Nauka, Moscow, 1968.

Felzer, K. R., T. W. Becker, R. E. Abercrombie, G. Ekstrom, and J. R. Rice, Triggering of the 1999 MW7.1 Hector Mine earthquake by aftershocks of the 1992 MW7.3 Landers earthquake, J. Geophys. Res., 107(B9), 2190, doi:10.1029/2001 JB000911, 2002.

Geller, R. J., D. D. Jackson, Y. Y. Kagan, and F. Mulargia, Earthquakes cannot be predicted, Science, 275, 1616-1617, 1997.

Gomberg, J., P. A. Reasenberg, P. Bodin, and R. A. Harris, Earthquake triggering by seismic waves following the Landers and Hector Mine earthquakes, Nature, 411, 462-466, 2001.

Harris, R. A. and R. W. Simpson, The 1999 MW7.1 Hector Mine, California, Earthquake: a test of the stress shadow hypothesis?, Bull. Seismol. Soc. Am., 92, 1497-1512, 2002.

Hergarten, S., Self-Organized Criticality in Earth Systems, 272 pp, SpringerVerlag, Berlin Heidelberg, 2002.

Iio, Y., T. Matsuzawa, S. Yoshida, T. Kato, and N. Hirata, Spatial and temporal changes of aseismic slip and its role on earthquake forecasting, Zisin, 56, 213-229, 2003.

Ishimoto, M. and K. Iida, Observations sur les séismes enregistrés par le microsismographe construit dernièrement, Bull. Earthquake Res. Inst. Univ. Tokyo, 17, 443-478, 1939 (in Japanese).

Ito, K. and M. Matsuzaki, Earthquakes as self-organized critical phenomena, J. Geophys. Res., 95, 6853-6868, 1990.

Jaumé, S. C. and L. R. Sykes, Evolving towards a critical point: a review of accelerating seismic moment/energy release prior to large and great earthquakes, Pure Appl. Geophys., 155, 279-305, 1999.

Kagan, Y. Y., Universality of the seismic moment-frequency relation, Pure Appl. Geophys., 155, 537-573, 1999.

Kanamori, H., The nature of seismicity patterns before large earthquakes, in Earthquake Prediction-An International Review, edited by D. W. Simpson and P. G. Richards, pp. 1-19, American Geophysical Union, Washington, D.C., 1981.

Main, I. G. and F. H. Al-Kindy, Entropy, energy and proximity to criticality in global earthquake populations, Geophys. Res. Lett., 29(7), 1121, doi:10.1029/2001GL014078, 2002.

McCann, W. R., S. P. Nishenko, L. R. Sykes, and J. Krause, Seismic gaps and plate tectonics: seismic potential for major plate boundaries, Pure Appl. Geophys., 117, 1082-1147, 1979.

Mellors, R. J., L. Sichoix, and D. T. Sandwell, Lack of precursory slip to the 1999 Hector Mine, California, earthquake as constrained by InSAR, Bull. Seismol. Soc. Am., 92, 1443-1449, 2002.

Mogi, K., Some discussions on aftershocks, foreshocks and earthquake swarms - the fracture of a semi-infinite body caused by an inner stress origin and its relation to the earthquake phenomena, Bull. Earthq. Res. Inst., 41, 615-658, 1963.

Murray, J. and P. Segall, Testing time-predictable earthquake recurrence by direct measurement of strain accumulation and release, Nature, 419, 287291, 2002.

Nakanishi, H., Cellular-automaton model of earthquakes with deterministic dynamics, Phys. Rev. A, 41, 7086-7089, 1990.

Olami, Z., H. J. S. Feder, and K. Christensen, Self-organized criticality in a continuous, non-conservative cellular automaton modeling earthquakes, Phys. Rev. Lett., 68, 1244-1247, 1992.

Page, E. S., Continuous inspection schemes, Biometrika, 41, 100-114, 1954. Pollitz, F. F. and I. S. Sacks, Stress triggering of the 1999 Hector Mine earthquake by transient deformation following the 1992 Landers earthquake, Bull. Seismol. Soc. Am., 92, 1487-1496, 2002.

Price, E. J. and R. Burgmann, Interactions between the Landers and Hector Mine, California, earthquakes from space geodesy, boundary element modelling, and time-dependent friction, Bull. Seismol. Soc. Am., 92, 1450-1469, 2002.

Reid, H. F., The mechanics of the earthquake, in The California earthquake of April 18, 1906, Report of the State Earthquake Investigation Commission, Carnegie Institution of Washington, Vol. 2, 1910.

Rhoades, D. A. and F. F. Evison, Long-range earthquake forecasting with every earthquake a precursor according to scale, Pure Appl. Geophys., 161, 47-72, 2004.

Roeloffs, E. and J. Langbein, The earthquake prediction experiment at Parkfield, California, Rev. Geophys., 32, 315-336, 1994.

Rong, Y., D. D. Jackson, and Y. Y. Kagan, Seismic gaps and earthquakes, J. Geophys. Res., 108(B10), 2471, doi:10.1029/2002JB002334, 2003.

Rundle, J. B., A physical model for earthquakes 3 . Thermodynamical approach and its relation to nonclassical theories of nucleation, J. Geophys. Res., 94, 2839-2855, 1989.

Rymer, M. J., J. Boatwright, L. C. Seekins, J. D. Yule, and J. Liu, Triggered surface slips in the Salton Trough associated with the 1999 Hector Mine, California, earthquake, Bull. Seismol. Soc. Am., 92, 1300-1317, 2002.

Scholz, C. H., The Mechanics of Earthquakes and Faulting, Cambridge U.P., 1990.

Scholz, C. H., Earthquakes and faulting: self-organised critical phenomena with a characteristic dimension, in Spontaneous Formation of Space-Time Structures and Criticality, Kluwer Academic Publishers, Netherlands, 41-56, 1991.

Stein, R. S., Parkfield's unfulfilled promise, Nature, 419, 257-258, 2002.

Turcotte, D. L., Fractals and Chaos in Geology and Geophysics, 2nd ed., 398 pp, Cambridge U.P., 1997.

Utsu, T., Aftershocks and earthquake statistics (II), J. Fac. Sci. Hokkaido Univ., Ser. 7, Geophysics, 3, 197-226, 1970.

Vidale, J. E. and Y.-G. Li, Damage to the shallow Landers fault from the nearby Hector Mine earthquake, Nature, 421, 524-526, 2003.

F. F. Evison (e-mail: Frank.Evison@vuw.ac.nz) and D. A. Rhoades (email: d.rhoades@gns.cri.nz) 